\title{
Features of adenosine metabolism of mouse heart
}

\author{
Andreas Deussen • Johannes Weichsel • Annette Pexa
}

Received: 2 December 2005 / Revised: 23 March 2006 / Accepted: 20 April 2006 / Published online: 21 July 2006

(C) Springer Science + Business Media B.V. 2006

\begin{abstract}
Adenosine metabolism and transport were evaluated in the isolated perfused mouse heart and compared with the well-established model of isolated perfused guinea pig heart. Coronary venous release of adenosine under well-oxygenated conditions in the mouse exceeds that in the guinea pig threefold when related to tissue mass. Total myocardial adenosine production rate under this condition was approximately $2 \mathrm{nmol} / \mathrm{min}$ per gramme and similar in both species. Coronary resistance vessels of mice are highly sensitive to exogenous adenosine, and the threshold for adenosine-induced vasodilation is approximately $30 \mathrm{nmol} / \mathrm{l}$. Adenosine membrane transport was largely insensitive to nitrobenzyl-thioinosine (NBTI) in mouse heart, which is in contrast to guinea pig and several other species. This indicates the dominance of NBTI-insensitive transporters in mouse heart. For future studies, the assessment of cytosolic and extracellular adenosine metabolism and its relationship with coronary flow will require the use of more effective membrane transport blockers.
\end{abstract}

Key words CD73 - guinea pig · knock-out models · membrane transport $\cdot$ myocardium

\section{Introduction}

The various roles of the purine adenosine for heart function have been described in detail [1-8]. The observed effects are mediated via activation of cell surface receptors, which are linked to various signal transduction pathways $[9,10]$.

\footnotetext{
A. Deussen $(\square) \cdot J$. Weichsel $\cdot$ A. Pexa

Department of Physiology, Medical Faculty of Carl Gustav Carus,

TU Dresden, Fetscherstrasse 74,

01307 Dresden, Germany

e-mail: Andreas.Deussen@tu-dresden.de
}

Many of the regulatory functions of adenosine have been assessed by classical blocking experiments of adenosine receptors or the use of receptor agonists. More recently, genetic knock-out and overexpression models have been developed, which permit an alternative approach to the evaluation of individual metabolic or signal transduction pathways (e.g., [11-15]).

Adenosine metabolism has been assessed in great detail by our group, using the model of the isolated, perfused guinea pig heart $[16,17]$. The experimental results permitted the development of a mathematical model of cardiac adenosine metabolism and transport [18], which has been proven to have predictive value for the design of consecutive studies on adenosine metabolism [19]. Unfortunately, such detailed data are missing for the mouse heart. Thus, interpretation of adenosine release and function determined in mouse heart $[20,21]$ has, so far, been restricted to the analysis of relative changes. So long as a comprehensive quantitative data set is lacking for mouse heart, the results of experiments of knock-out and overexpression models should be interpreted with great caution.

The present report pinpoints potential differences in metabolism and transport of adenosine between mouse and guinea pig heart. The goal was to provide a base for detailed planning of future experiments aiming to provide a comprehensive data set describing cytosolic and extracellular adenosine metabolism in quantitative terms. Such a data set might then permit calculation of adenosine concentrations at cell surface receptors as well as transmembranous concentration gradients in mouse myocardium.

\section{Materials and methods}

Hearts were taken from mice anaesthetised with urethane (1.5 mg/kg i.p.). Under a dissection microscope (magnifica- 
tion $\times 15$ ) the ascending aorta was cannulated with stainless steel tubing $(1 \mathrm{~mm}$ o.d.) in a retrograde direction. The aortic cannula was then fixed to a perfusion line providing a modified Krebs buffer [containing $(\mathrm{mM}): 119 \mathrm{NaCl}, 4.56$ $\mathrm{KCl}, 1.2 \quad \mathrm{MgSO}_{4} 1.18 \mathrm{KH}_{2} \mathrm{PO}_{4}, 24.9 \mathrm{NaHCO}_{3}, 8.27$ glucose, 2.0 pyruvate, $0.65 \mathrm{EDTA}$ and $3.0 \mathrm{CaCl}_{2}$ ] bubbled through with carbogen $\left(95 \% \mathrm{O}_{2}\right.$ and $5 \% \mathrm{CO}_{2}$ at ambient pressure) and kept at $37^{\circ} \mathrm{C}$ [16]. Next, a small polyethylene balloon connected to a thin polyethylene catheter $(0.96 \mathrm{~mm}$ o.d.) was advanced into the left ventricle via the left atrium for measurement of isovolumic pressure development. A thin polyethylene catheter was advanced into the right ventricle for collection of the coronary venous effluent perfusate. Two silver electrodes were fixed to the atria for pacing at $500 \mathrm{bpm}$. The perfusion pressure was set to $85 \mathrm{mmHg}$ and kept constant during the entire experiment. Coronary flow was measured with a flow probe (diameter $1 \mathrm{~mm}$, Altron Medical Electronics, Fuerstenfeldbruck, Germany) connected to a flowmeter (Transonic Systems, Ithaca, USA) inserted into the perfusion line approximately $2 \mathrm{~cm}$ above the aortic cannula. Just below the flow probe perfusion pressure was measured with a transducer (Gould, Statham, USA). The haemodynamic data were continuously monitored via an interface on a $\mathrm{PC}$, using Ponemah data acquisition software (LDS Test and Measurement, Ismaning, Germany). Steady state values of coronary flow were reached after approximately $20 \mathrm{~min}$ (Figure 1). Initially elevated flow was most likely due to ischaemia during preparation. The following flow decline, together with an acute flow rise in response to a $20 \mathrm{~s}$ complete flow stop, was taken as an index of successful heart perfusion. Under these conditions, mouse hearts typically extracted $72 \%$ of the arterial oxygen supply.

The adenosine concentration of the coronary effluent perfusate collected over periods of $1 \mathrm{~min}$ was assessed as follows: $500 \mu \mathrm{l}$ of effluent perfusate was run over Sep-PAK columns as described [22] to increase the adenosine concentration of the sample and remove salts. The column eluate was dried and redissolved in $143 \mu$ ldeionised water, in which adenosine was converted to $1, \mathrm{~N}^{6}$-etheno-adenosine as described previously $[23,24]$. The concentration of etheno-adenosine was measured using established HPLC techniques with fluorescence detection [23, 24].

The results of the experiments performed on mouse hearts were averaged (mean \pm SEM) and compared with results from guinea pig heart experiments published before [19].

\section{Results and discussion}

Mouse hearts perfused under a constant pressure of $85 \mathrm{mmHg}$ and paced at a rate of $500 \mathrm{bpm}$ developed a left ventricular systolic pressure of $81 \pm 4 \mathrm{mmHg}$ and a left ventricular $\mathrm{dP} / \mathrm{dt}_{\max }$ of $3,634 \pm 152 \mathrm{mmHg} / \mathrm{s}$. Coronary flow was $9.9 \pm 0.4 \mathrm{ml} / \mathrm{min}$ per gramme and adenosine release averaged $156 \pm 13 \mathrm{pmol} / \mathrm{min}$ per gramme $(n=23)$. Thus, coronary venous adenosine concentration averaged $15.7 \mathrm{nmol} / \mathrm{l}$. When compared with guinea pig heart [19], which displays a significantly lower heart rate (approximately $250 \mathrm{bpm}$ ) and has a similar left ventricular pressure development (approx. $85 \mathrm{mmHg}$ ) but a lower $\mathrm{dP} / \mathrm{dt}_{\max }$ $(1,440 \mathrm{mmHg} / \mathrm{s})$, coronary flow rate and cardiac adenosine release rate of mouse heart are higher when related to the same mass of myocardial tissue [19]. Because the difference in coronary venous adenosine release between both species is considerably larger than the difference in flow rate, mouse hearts displayed a significantly higher coronary venous adenosine concentration than guinea pig hearts.

Generally higher concentrations of coronary venous adenosine have been reported by others [20]. In their experiments, however, only minor differences between mouse, rat and guinea pig hearts were observed. Potentially, differences in cardiac function may have contributed to this difference. In our experiments the hearts beat at a higher
Figure 1 Typical registration of coronary flow (upper panel) and myocardial contractility (lower panel). The registration starts at the time point of reperfusion. Following a reperfusion of $30 \mathrm{~min}$, a $20 \mathrm{~s}$ complete flow stop is induced to challenge coronary vessel dilation, which permits a flow rise approximately 3.8 -fold above control. Infusion of adenosine at concentrations of $80 \mathrm{nmol} / \mathrm{l}$ and $200 \mathrm{nmol} / \mathrm{l}$ results in profound increases of coronary flow, which are well reversible upon discontinuation of the infusion

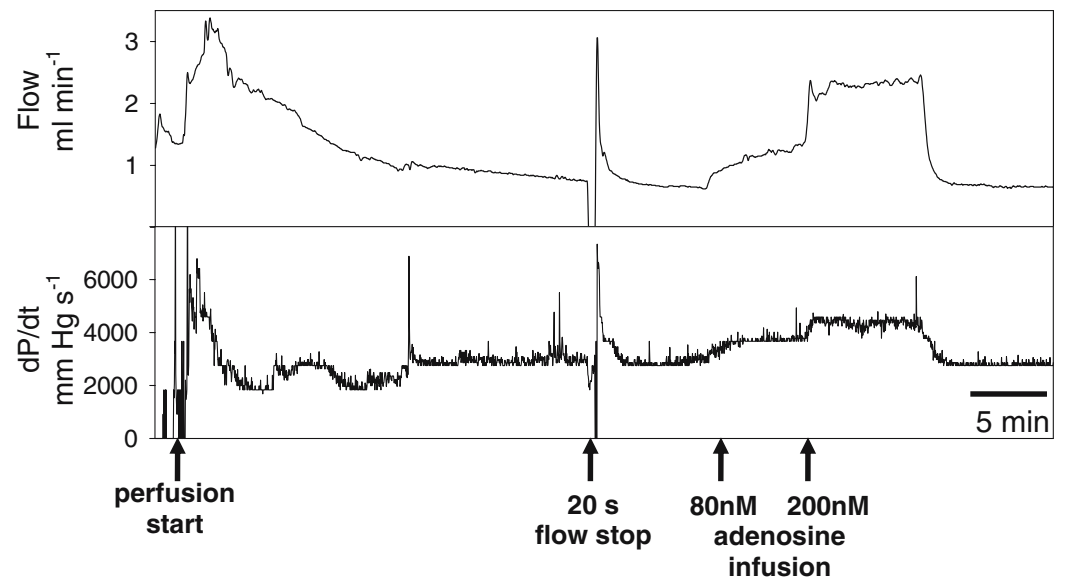


rate, but diastolic pressure was adjusted to result in lower pressure development. This experimental feature was adjusted in order not to exceed coronary perfusion pressure by left ventricular systolic pressure, which may have resulted in myocardial hypoperfusion.

Adenosine produced in the myocardium is catabolised either by phosphorylation to 5'-AMP via cytosolic adenosine kinase or by deamination to inosine via adenosine deaminase. Recently, Headrick and co-workers [20] have provided experimental evidence that in mouse heart the adenosine flux via the kinase pathway exceeds that via the deaminase pathway under control conditions. In addition to a cytosolic location, adenosine deaminase has been described as being associated with the membrane fraction in rabbit heart [25], and an isoform is found in blood plasma [26]. However, the latter aspect is not important for the scope of studies using buffer perfused hearts. A potential influence of adenosine deaminase activity bound to the outer leaflet of plasma membrane to global adenosine production of the mouse heart must remain open at present due to missing data.

We estimated the global mouse heart adenosine production rate by applying iodotubericidine (ITU, $10 \mu \mathrm{M}$ ), a powerful blocker of adenosine kinase, and erythro-9hydroxy-adenine (EHNA, $5 \mu \mathrm{M}$ ), a powerful blocker of adenosine deaminase. In response to the combined infusion of both inhibitors the coronary venous adenosine release was severely augmented by $841 \%$ (Figure 2) and coronary flow increased threefold. Preliminary experiments showed that this flow increase induced by EHNA and ITU was diminished to approximately $40 \%$ in the presence of the $\mathrm{A}_{2 \mathrm{~A}}$-receptor antagonist ZM241385. In contrast, infusion of the $\mathrm{A}_{1}$-receptor antagonist (8-cyclopentyl-1-1,3-dipropylxanthine, DPCPX) did not blunt the flow response. Thus, the response was mediated by $\mathrm{A}_{2 \mathrm{~A}}$-adenosine receptors.

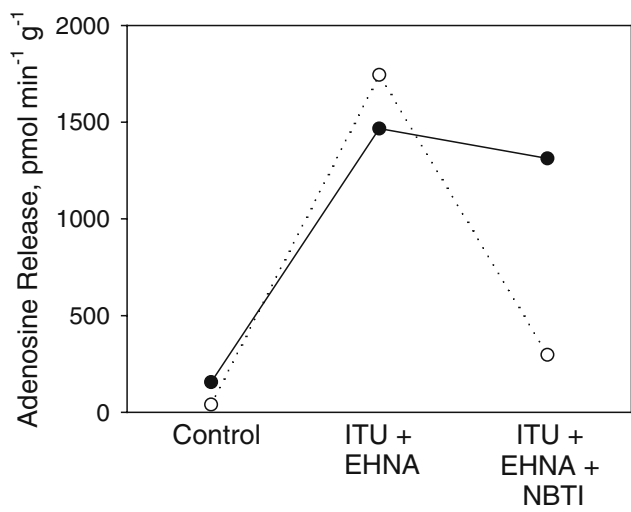

Figure 2 Effects of combined infusion of ITU $(10 \mu \mathrm{M})$ and EHNA $(5 \mu \mathrm{M})$ and additional infusion of nitrobenzyl-thioinosine $(N B T I)$ on cardiac adenosine release. Combined administration of ITU and EHNA steeply increased adenosine release in mouse hearts (black circles) and guinea pig hearts (open circles). Additional administration of NBTI $(10 \mu \mathrm{M}$ in mouse, $1 \mu \mathrm{M}$ in guinea pig) only decreased adenosine release in guinea pig heart
The results of the combined block of adenosine kinase and adenosine deaminase obtained in mouse heart are similar to those measured under equivalent conditions in guinea pig heart $[19,20]$. The release under the combined block of adenosine kinase and adenosine deaminase may be taken as a minimum estimate of the global cardiac adenosine production rate. Although both competitive blockers are highly effective in the concentrations used [19], their efficacy probably decreases when the adenosine concentration rises. For guinea pig myocardium we had previously measured a coronary venous release rate of $1,744 \pm 518 \mathrm{pmol} / \mathrm{min}$ per gramme under the conditions of combined block of adenosine kinase and adenosine deaminase. Simulation of this adenosine release rate by mathematical model analysis required a global adenosine production rate of $2,295 \mathrm{pmol} / \mathrm{min}$ per gramme [19]. Thus, adenosine production estimated directly from adenosine release data may be underestimated by $30 \%$. If this result is applied to mouse heart, a global adenosine production rate of approximately $2,000 \mathrm{pmol} / \mathrm{min}$ per gramme may be assumed. Thus, similar to the conclusions reported for guinea pig heart before [19], such a high adenosine production rate exceeds adenosine release rate under basal well-oxygenated conditions 13-fold.

Purines are transported across membranes via transport proteins, which permit facilitative diffusion (non-concentrative or equilibrative nucleoside transporters) or act as secondary active transporters using the sodium concentration difference (concentrative nucleoside transporters) [27]. The inhibition of membrane transport for adenosine has been suggested to be of potential beneficial function under a multitude of pathological conditions, because the interstitial adenosine concentration is increased under membrane transport block [28]. Typically, in heart tissue, equilibrative nucleoside transport of adenosine exists $[29,30]$. Based on the efficacy of nitrobenzyl-thioinosine (NBTI) to inhibit membrane transport, two equilibrative transport systems may be differentiated. The first is highly sensitive to inhibition by NBTI $(<1 \mu \mathrm{M})$; the second is rather insensitive to NBTI $(>1 \mu \mathrm{M})$. In guinea pig and rat myocardium the effectiveness of NBTI suggests that the highly sensitive equilibrative nucleoside transport is largely responsible for adenosine transport [29]. Similar results have been obtained with dipyridamole $(1 \mu \mathrm{M})$ or draflazine $(1 \mu \mathrm{M})$ [19]. The inhibitory effect can be demonstrated for net myocardial adenosine release as well as for net adenosine uptake, reflecting the concept that adenosine transport via this nucleoside transport is equilibrative.

Purine transport systems of mouse tissues have been studied only very recently [30]. It may be of particular importance that mouse heart not only exhibits mRNA for equilibrative transport proteins but also for at least two different concentrative nucleoside transporters. Whether the respective transport proteins are expressed and functionally 
active has not been determined to date. It should be noted that NBTI-sensitive binding sites in mouse heart ventricular tissue were shown to be lower, by a factor of 4 , than in guinea pig heart ventricle. The dissociation constant for NBTI binding in mouse myocardium was considerably lower than in guinea pig myocardium [31]. This suggests fewer NBTI-sensitive membrane transporters with a lower affinity for NBTI in mouse myocardium.

The efficacy of NBTI to block adenosine membrane transport was studied in our mouse heart experiments. The cytosolic adenosine concentration was raised by simultaneous application of the blockers for adenosine kinase and adenosine deaminase, iodotubercidine and EHNA, respectively. Under this condition adenosine release rate was largely elevated, as pointed out above. Co-infusion of NBTI $(10 \mu \mathrm{M})$ did not significantly alter this elevated adenosine release. This result is in contrast to that obtained in guinea pig hearts, in which a concentration of $1 \mu \mathrm{M}$ was highly effective to block adenosine release under this condition (Figure 2). It indicates that membrane transport differs remarkably in mouse heart as compared to guinea pig heart and rat heart. In additional experiments using $100 \mu \mathrm{M}$ NBTI coronary perfusion pressure was severely increased, which precluded a meaningful interpretation of adenosine release, which was decreased under this condition. Whether NBTI sensitivity of mouse equilibrative nucleoside transport proteins differs from that of the other species, or whether concentrative nucleoside transport proteins play an additional role in mouse heart, remains to be determined.

The adenosine concentration in the coronary effluent perfusate of mouse heart averaged $15.7 \mathrm{nmol} / 1$ under welloxygenated control conditions. Headrick and associates [20] have reported a notably higher concentration of $57 \pm 14 \mathrm{nM}$. The effects of $\mathrm{A}_{2 \mathrm{~A}}$-receptor antagonists on baseline coronary flow of mouse heart have been reported previously. Those authors reported a decrease in coronary flow of $9 \%$ in wild type mice [32]) and of even $25 \%$ in an $\mathrm{A}_{3}$-receptor knock-out mouse model [33]. Unfortunately, no measurements of adenosine release were reported in those studies. It is thus not possible to relate these flow effects to the available release data. However, the data suggest that adenosine may regulate coronary flow of mouse heart under well-oxygenated conditions.

In a first set of experiments we have addressed the apparent mouse coronary vessel responsiveness for adenosine (Figure 3). Adenosine, in a dose-dependent fashion, increased coronary flow. At the highest concentrations used $(0.8 \mu \mathrm{M})$ coronary flow increased threefold, which shows that adenosine is a powerful vasodilator of mouse coronary vessels. Threshold concentration for flow increase was between $20 \mathrm{nmol} / \mathrm{l}$ and $40 \mathrm{nmol} / \mathrm{l}$. This concentration range is slightly higher than the venous adenosine concentration determined under well-oxygenated conditions $(15.7 \mathrm{nmol} / \mathrm{l})$.

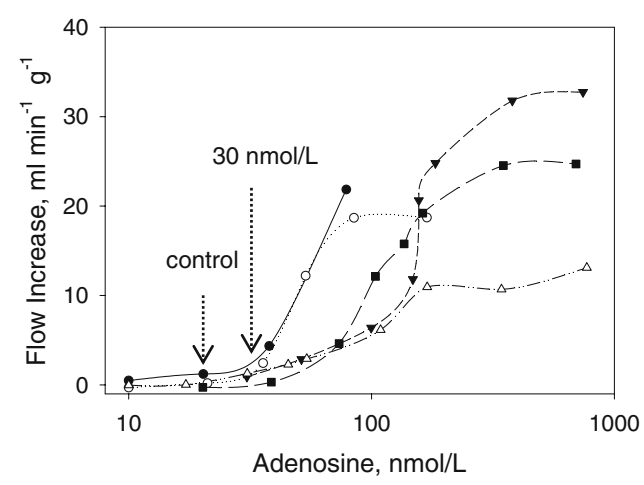

Figure 3 Concentration-effect relationship for exogenous adenosine and coronary flow of mouse heart. Data from five experiments indicated by different symbols are shown

These results indicate that, if adenosine controls baseline coronary flow of mouse heart, the net effect should be rather small. However, because the coronary effluent adenosine concentration is only slightly below the adenosine concentration necessary to evoke a threshold coronary flow increase, it appears possible that minor increases of the adenosine production rate are effective to drive the adenosine concentration into the vasodilatory range. While the data from Talukder and co-workers suggest a role of adenosine for mouse heart coronary flow regulation under control physiological conditions (isolated heart), data from Tune and coworkers [34], obtained in the dog heart in situ, indicate that adenosine is unimportant for the control of resting coronary blood flow. Moreover, this group has addressed the potential role of adenosine under a wide variety of physiological (exercise, [33]) and pathophysiological conditions (hypoxia) [35]. Only under conditions of hypoxia did these authors report evidence of a role for adenosine in coronary flow regulation. These data are, however, are in conflict with data reported by Duncker and co-workers for pig heart [36], who found evidence of control of coronary oxygen extraction by adenosine under baseline physiological conditions. Furthermore, they reported evidence of parallel, rather than redundant, flow control mechanisms involving adenosine, NO, and KATP channels [37]. While species differences may exist, it seems of importance to clarify whether myocardial oxygen extraction is controlled by adenosine in mouse heart. Such experiments should include measurements of the adenosine concentration, because pharmacological block of the adenosine receptors may result in an increase in the adenosine production rate and, consecutively, of the interstitial adenosine concentration, which may reduce the efficacy of the receptor blockade.

Following detailed experimentation on guinea pig heart and consecutive mathematical model analysis we hypothesised that the adenosine concentration gradient falls from extracellular to cytosolic under well-oxygenated conditions [19]). The model analysis also suggested that ecto-5'- 
nucleotidase (CD73) was of great relevance for establishing this concentration gradient. Meanwhile, Koszalka and coworkers [15] created a knock-out mouse for CD73. They reported that coronary flow rate of $\mathrm{CD} 73-/-$ hearts under well-oxygenated conditions was significantly $(-14 \%)$ lower than that of wild type hearts. This result indicates that membrane transport of adenosine was ineffective in adjusting for the decreased extracellular adenosine production rate by permitting increased cellular efflux of adenosine following the reduction of interstitial adenosine concentration. In order to clarify this concept it will be necessary to develop protocols that permit the blocking of membrane transport of mouse heart effectively.

In conclusion, we have started to assess adenosine metabolism and transport of mouse heart. With respect to global adenosine production rates, mice hearts are similar to guinea pig hearts. However, membrane transport of adenosine largely differs between both species. The classical inhibitor NBTI, which is highly effective in various species, does not inhibit membrane transport of adenosine in mouse heart effectively. These results might be attributed to insensitivity of the transport protein to NBTI due to a different amino acid sequence. Another possibility is that entirely different transporters (e.g., concentrative transport proteins) control adenosine membrane transport in the mouse heart. This question remains to be clarified in the future. Finally, mouse heart exhibits high sensitivity to adenosine with respect to coronary flow regulation. Experiments are in progress to test whether this sensitivity is of importance for flow control or oxygen extraction in mouse heart under physiological and pathophysiological conditions.

\section{References}

1. Hori M, Kitakaze M (1991) Adenosine, the heart, and coronary circulation. Hypertension 18:565-574

2. Shryock JC, Belardinelli L (1997) Adenosine and adenosine receptors in the cardiovascular system: biochemistry, physiology, and pharmacology. Am J Cardiol 79:2-10

3. Sommerschild HT, Kirkeboen KA (2000) Adenosine and cardioprotection during ischaemia and reperfusion - an overview. Acta Anaesthesiol Scand 44:1038-1055

4. Mubagwa K, Flameng W (2001) Adenosine, adenosine receptors and myocardial protection: an updated overview. Cardiovasc Res 52:25-39

5. Baxter GF (2002) Role of adenosine in delayed preconditioning of myocardium. Cardiovasc Res 55:483-494

6. Burnstock G (2002) Potential therapeutic targets in the rapidly expanding field of purinergic signalling. Clin Med 2:45-53

7. Donato M, Gelpi RJ (2003) Adenosine and cardioprotection during reperfusion - an overview. Mol Cell Biochem 251:153-159

8. Schindler CW, Karcz-Kubicha M, Thorndike EB, Mueller CE, Tella SR, Ferrè S, Goldberg SR (2005) Role of central and peripheral adenosine receptors in the cardiovascular responses to intraperitoneal injections of adenosine $A_{1}$ and $A_{2 A}$ subtype agonists. Br J Pharmcol 144:642-650
9. Olsson RA, Pearson JD (1990) Cardiovascular purinoceptors. Physiol Rev 70:761-845

10. Schulte G, Fredholm BB (2003) Signalling from adenosine receptors to mitogen-activated protein kinases. Cell Signal 15:813-827

11. Matherne GP, Linden J, Byford AM, Gauthier NS, Headrick JP (1997) Transgenic A1 adenosine receptor overexpression increases myocardial resistance to ischemia. Proc Natl Acad Sci USA 94:6541-6546

12. Sala-Newby GB, Skladanowski AC, Newby AC (1999) The mechanism of adenosine formation in cells. Cloning of cytosolic 5'-nucleotidase-I. J Biol Chem 274:17789-17793

13. Salvatore CA, Tilley SL, Latour AM, Fletcher DS, Koller BH, Jacobson MA (2000) Disruption of the A(3) adenosine receptor gene in mice and its effect on stimulated inflammatory cells. J Biol Chem 275:4429-4434

14. Johansson B, Halldner L, Dunwiddie TV, Masino SA, Poelchen W, Gimenez-Llort L, Escorihuela RM, Fernadez-Teruel A, Wiesenfeld-Hallin Z, Xu XJ, Hardemark A, Betsholtz C, Helenius E, Fredholm BB (2001) Hyperalgesia, anxiety, and decreased hypoxic neuroprotection in mice lacking the adenosine A1 receptor. Proc Natl Acad Sci USA 98:9407-9412

15. Koszalka P, Ozuyaman B, Huo Y, Zernecke A, Flogel U, Braun N, Buchheiser A, Decking UK, Smith ML, Sevigny J, Gear A, Weber AA, Molojavyi A, Ding Z, Weber C, Ley K, Zimmermann H, Godecke A, Schrader J (2004) Targeted disruption of cd73/ecto5 -nucleotidase alters thromboregulation and augments vascular inflammatory response. Circ Res 95:814-821

16. Deussen A, Borst M, Schrader J (1988) Formation of Sadenosylhomocysteine in the heart. I: an index of free intracellular adenosine. Circ Res 63:240-249

17. Deussen A, Lloyd HGE, Schrader J (1989) Contribution of Sadenosylhomocysteine to cardiac adenosine formation. J Mol Cell Cardiol 21:773-782

18. Kroll K, Deussen A, Sweet I (1992) Comprehensive model of transport and metabolism of adenosine and S-adenosylhomocysteine in the guinea pig heart. Circ Res 71:590-604

19. Deussen A, Stappert M, Schäfer S, Kelm M (1999) Quantification of extracellular and intracellular adenosine production. Understanding the transmembranous concentration gradient. Circulation 99:2041-2047

20. Headrick JP, Peart J, Hack B, Garnham B, Martherne GP (2001) 5'Adenosine monophosphate and adenosine metabolism, and adenosine responses in mouse, rat and guinea pig heart. Comp Biochem Physiol A Mol Integr Physiol 130:615-631

21. Peart J, Matherne GP, Cerniway RJ, Headrick JP (2001) Cardioprotection with adenosine metabolism inhibitors in ischemic-reperfused mouse heart. Cardiovasc Res 52:120-129

22. Deussen A, Möser G, Schrader J (1986) Contribution of coronary endothelial cells to cardiac adenosine production. Pflügers Arch 406:608-614

23. Haink G, Deussen A (2003) Liquid chromatography method for the analysis of adenosine compounds. J Chromatography B 784:189-193

24. Pexa A, Deussen A (2005) Modulation of ecto- $5^{\prime}$-nucleotidase by phospholipids in human umbilical vein endothelial cells (HUVEC). Naunyn-Schmiedebergs Arch Pharmacol 372:131-138

25. Schrader WP, West CA (1990) Localization of adenosine deaminase and adenosine deaminase complexing protein in rabbit heart. Implications for adenosine metabolism. Circ Res 66:754-762

26. Ungerer JP, Oosthuizen HM, Bissbort SH, Vermaak WJ (1992) Serum adenosine deaminase: isoenzymes and diagnostic application. Clin Chem 38:1322-1326

27. Jarvis SM (1987) Kinetic and molecular properties of nucleoside transporters in animal cells. In: Gerlach E, Becker BF (eds) Topics and perspectives in adenosine research. Springer, Berlin Heidelberg New York, pp 102-117 
28. Noji T, Karasawa A, Kusaka H (2004) Adenosine uptake inhibitors. Eur J Pharmacol 495:1-16

29. Clanachan AS, Heaton TP, Parkinson FI (1987) Drug interactions with nucleoside transport systems. In: Gerlach E, Becker BF (eds) Topics and perspectives in adenosine research. Springer, Berlin Heidelberg New York, pp 118-130

30. Lu H, Chen C, Klaasen C (2004) Tissue distribution of concentrative and equilibrative nucleoside transporters in male and female rats and mice. Drug Metab Dispos 32:1455-1461

31. Williams EF, Barker PH, Clanachan AS (1984) Nucleoside transport in heart: Species differences in nitrobenzylthioinosine binding, adenosine accumulation, and drug-induced potentiation of adenosine action. Can J Physiol Pharmacol 62:31-37

32. Talukder HMA, Morrison RR, Mustafa SJ (2002) Comparison of vascular effects of adenosine in isolated mouse heart and aorta. Am J Physiol Heart Circ Physiol 282:H49-H57
33. Talukder HMA, Morrison RR, Jacobson MA, Jacobson KA, Ledent C, Mustafa SJ (2002) Targeted deletion of adenosine $A_{3}$ receptors augments adenosine-induced coronary flow in isolated mouse hearts. Am J Physiol Heart Circ Physiol 282:H2183-H2189

34. Tune JD, Richmond KN, Gorman MW, Feigl EO (2002) Control of coronary blood flow during exercise. Exp Biol Med 227(4):238-250

35. Herrmann SC, Feigl EO (1992) Adrenergic blockade blunts adenosine concentration and coronary vasodilation during hypoxia. Circ Res 70:1203-1216

36. Duncker DJ, Stubenitsky R, Verdouw PD (1998) Role of adenosine in the regulation of coronary blood flow in swine at rest and during treadmill exercise. Am J Physiol 275:H1663-H1672

37. Merkus D, Haitsma DB, Fung TY, Assen YJ, Verdouw PD, Duncker DJ (2003) Coronary blood flow regulation in exercising swine involves parallel rather than redundant vasodilator pathways. Am J Physiol Heart Circ Physiol 285:H424-H433 